\title{
Analysis of synthetic aperture radar data collected over the southwestern Greenland ice sheet
}

\author{
K. C. JEZEK, \\ Byrd Polar Research Center and Department of Geological Sciences, The Ohio State University, Columbus, Ohio 43210, U.S.A. \\ M. R. Drinkwater, J. P. Crawford, \\ Jet Propulsion Laboratory, California Institute of Technology, Pasadena, California 91109, U.S.A. \\ R. BINDSCHADLER, \\ Goddard Space Flight Center, Greenbelt, Maryland 20771, U.S.A. \\ R. KWOK \\ Jet Propulsion Laboratory, California Institute of Technology, Pasadena, California 91109, U.S.A.
}

\begin{abstract}
Analyses of the first aircraft multi-frequency, polarimetric synthetic aperture radar (SAR) data acquired over the southwestern Greenland ice sheet are presented. Data were collected on 31 August 1989 by the Jet Propulsion Laboratory SAR using the NASA DC-8 aircraft. Along with curvilinear patterns associated with large-scale morphologic features such as crevasses, lakes and streams, frequency and polarization dependencies are observed in the P-, L- and C-band image products. Model calculations that include firn grain-size and volumetric water content suggest that tonal variations in and between the images are attributable to large-scale variations in the snow- and ice-surface characteristics, especially snow wetness. In particular, systematic trends in back-scatter strength observed at C-band across regions of changing snow wetness are suggestive of a capability to delineate boundaries between snow facies. Ice lenses and ice pipes are the speculated cause for similar trends in P-band back-scatter. Finally, comparison between SEASAT SAR data collected in 1978 and these airborne data collected in 1989 indicate a remarkable stability of surface patterns associated with the locations of supraglacial lake and stream systems.
\end{abstract}

\section{INTRODUGTION}

Over the past 4 years, there have been several opportunities to test the utility of synthetic aperture radar (SAR) for studying polar ice sheets. Much of the interest in SAR for ice-sheet studies was stimulated by the analysis of data collected by the SEASAT satellite-borne L-band SAR, which suggested the possibility for using SAR in mapping and monitoring studies. Though a limited amount of data was collected by SEASAT, it was clear that the ice margin and features of dynamic significance could be mapped. Also, the varying texture and back-scatter strength indicated that the extent of the different snow facies on the ice sheet could be monitored. Bindschadler and others (1987) discussed the SEASAT data along with more recently collected single-polarization X-band SAR data acquired by aircraft flying over northwestern and southern Greenland. They interpreted many of the features in the imagery as relating to glacial hydrology, including surface lakes and stream systems. Complex mottling of the surface was interpreted as an effect associated with topographic relief, an explanation adopted by Molnia and Jones (1989) who have studied airborne X-band and SEASAT L-band SAR data collected over Malaspina Glacier in Alaska.

In this paper, we present data collected on 31 August 1989 over southern Greenland (Fig. 1) using the Jet Propulsion Laboratory (JPL) three-frequency, polarimetric SAR. C-, L- and P-band data (5.3, 1.2 and $0.4 \mathrm{GHz}$, respectively) were collected at linear like- $(\mathrm{HH}$, $\mathrm{VV})$ and cross- (HV, $\mathrm{VH})$ polarizations. Thus far, survey images $(25 \mathrm{~m}$ resolution with a $4.5 \mathrm{~km}$ wide ground swath) have been produced from digital data acquired along a large proportion of the flight tracks. A few fourlook, $12 \mathrm{~km} \times 8 \mathrm{~km}$ slant range, antenna-pattern corrected images (with a resolution of $12 \mathrm{~m}$ in azimuth by $7 \mathrm{~m}$ in range) have, for selected regions, been processed to full resolution on the basis of ice-surface characteristics in the survey data. A limited amount of synoptic data, which are spatially extensive along track with full resolution and $12 \mathrm{~km}$ swath width (but with the restriction of only three channels in frequency and 


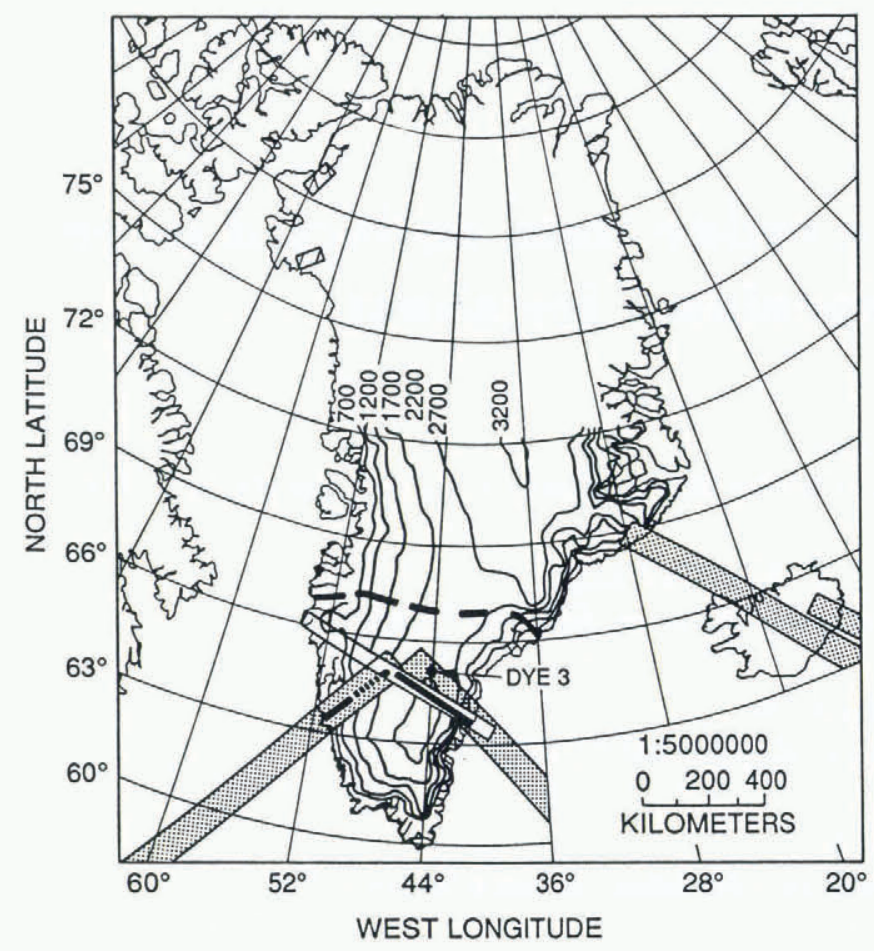

polarization), have also been processed and slant range corrected. All image-data products yield images rich in texture and contrast.

\section{GLACIAL SETTING}

Data discussed in this paper were collected along the heavy, broken line in the southwestern part of the ice sheet (Fig. 1); the high-resolution scene (Fig. 5) is located at about $64^{\circ} 30.7^{\prime} \mathrm{N}, 48^{\circ} 48.7^{\prime} \mathrm{W}$. Additional data were

Fig. 1. Map of Greenland showing areas imaged by SEASAT (stippled), airborne $X$-band SAR (hatched areas in northwest Greenland and open rectangle in southern Greenland), and the FPL multi-channel SAR (heavy lines). Data discussed in this paper were collected along the heavy dashed lines located within the SEASAT swath taken over southwestern Greenland.

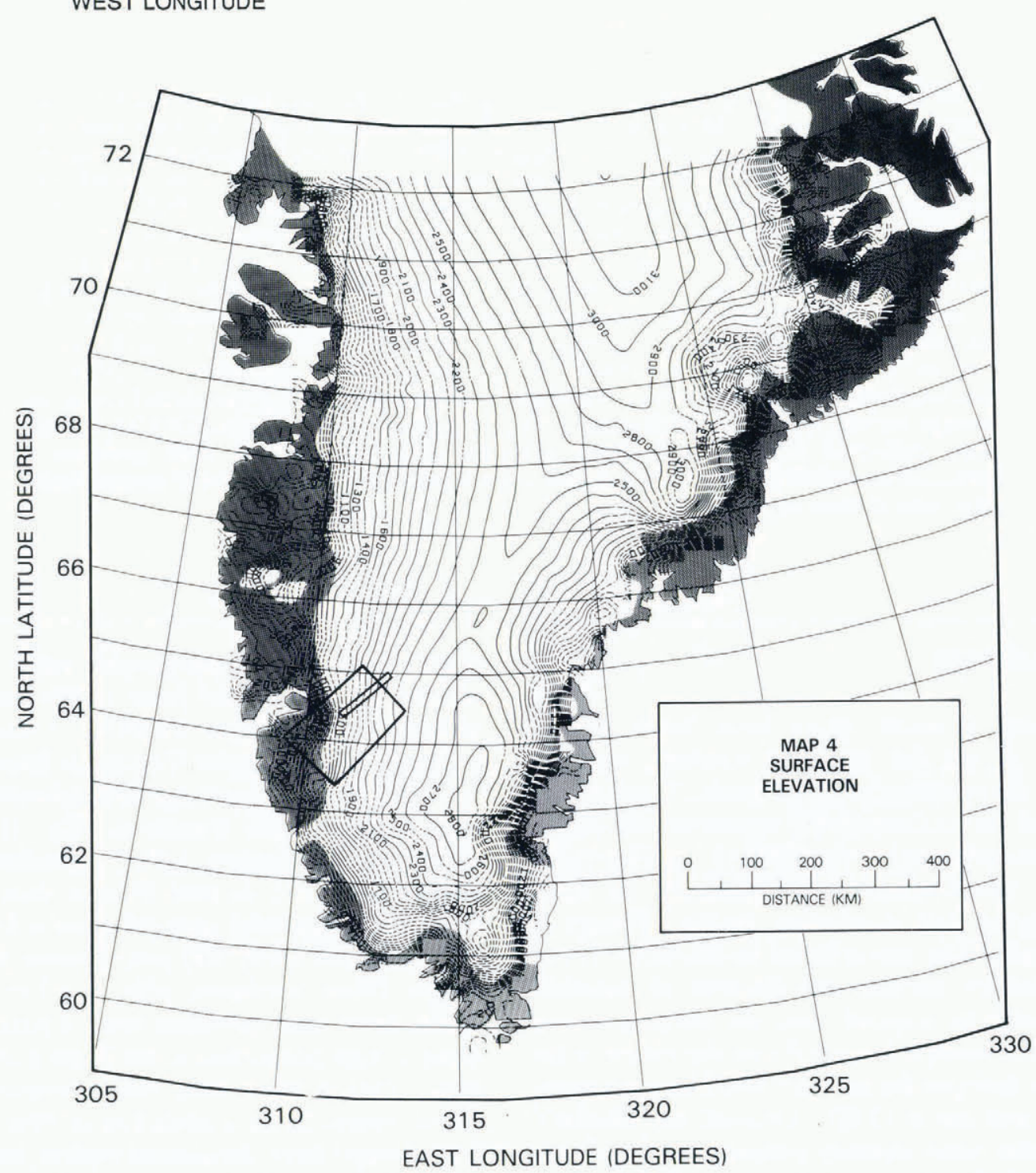

Fig. 2. Elevation map of southern Greenland compiled from satellite-altimeter data (from Bindschadler and others, 1989). JPL multi-channel SAR data were collected within the thin rectangle. The large rectangle represents the area in which SEASAT SAR data were acquired. 
collected in 1989 (heavy dashed-line segments north of $66^{\circ}$ in Figure 1) but are not discussed here. The locations of all other available SAR data, including SEASAT Lband SAR and Intera X-band airborne SAR data, are also shown in Figure 1. As illustrated in Figure 2, the most easterly point of the data set has an elevation of about $2200 \mathrm{~m}$. Data were collected down-glacier to a minimum elevation of about $1500 \mathrm{~m}$, near the equilibrium line of the ice sheet. The upper layers of the ice sheet in this area have distinct physical properties which are primarily

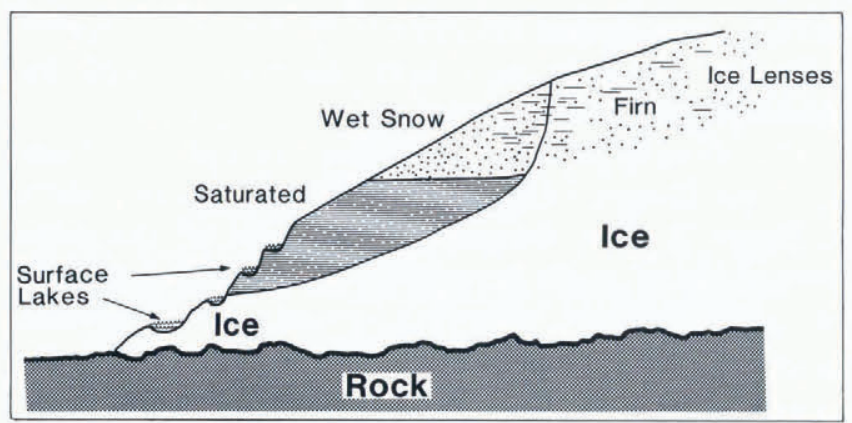

Fig. 3. Schematic representation of different snow facies present on the Greenland ice sheet. associated with the seasonal presence of free water in the snow and firn. Benson (1961) has categorized different snow facies for Greenland and a schematic diagram showing the snow facies likely to be encountered on this part of the ice sheet are shown in Figure 3. At the highest elevations where SAR data were collected, the snow is driest (though still not in the dry-snow zone as defined by Benson). Descending down-glacier, more ice lenses and wet snow are encountered. A water table may be present at depth. At lower elevations, the water table intercepts the surface and the snow is saturated with enough water to produce surface ponds and lakes in topographic depressions on the ice-sheet surface. Near the margin of the ice sheet, ablation by summer melting exposes bubbly ice which may be covered by a veneer of snow in winter. Free water is only present in the summer months; the effect of water is still recorded in the glacier during the winter by the number of ice lenses and pipes present in the accumulation region of the glacier, and by the shallow firn layer in the upper ablation area at lower elevations of the ice sheet.

\section{SAR DATA}

Flexibility in the processing schemes for converting raw SAR data to images results in several possible image products with attributes selectable on the basis of their

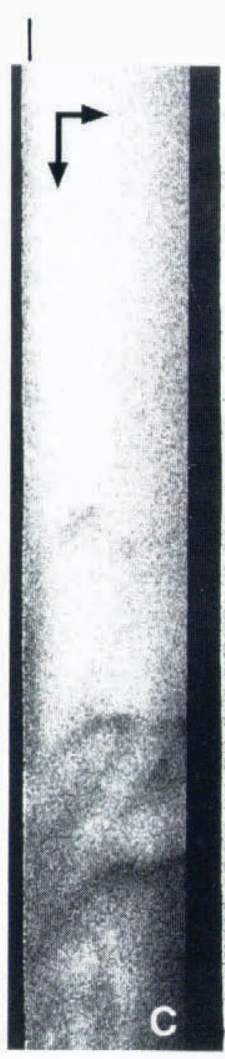

(i)

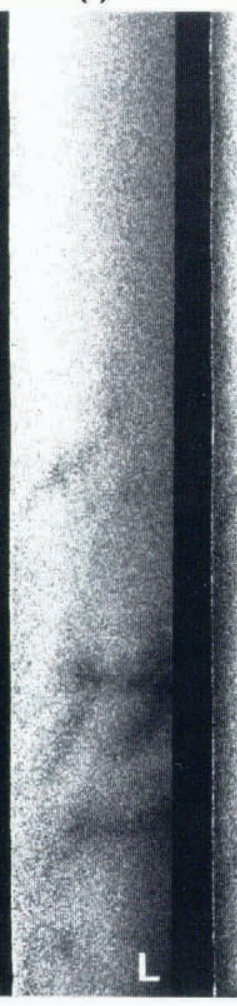

(ii)

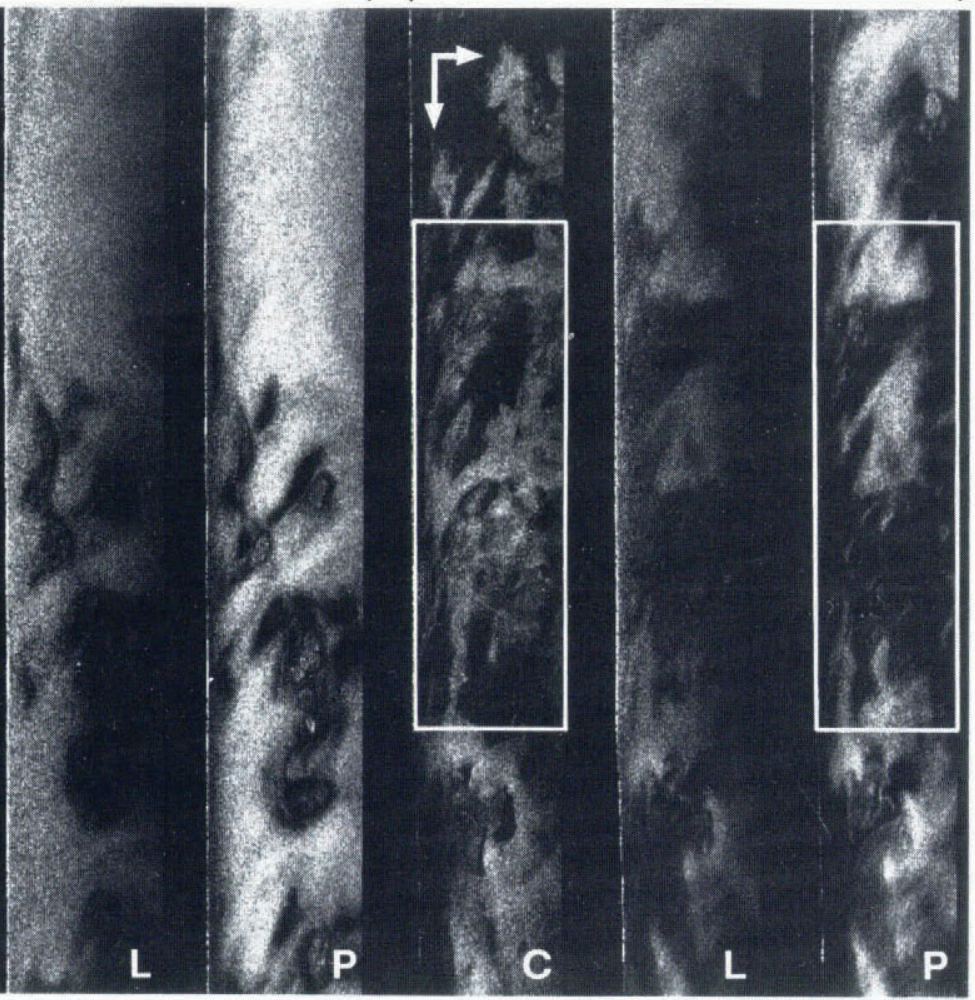

Fig. 4. C-, $L$ - and P-band survey-product data averaged over each polarization to reduce speckle. Three groups of $C$-, $L$ and $P$-band slant-range images are shown for comparison of the different frequency data. The aircraft flight and radarimaging directions are indicated by the along-track (vertical) and across-track (horizontal) arrows, respectively, and the swath width of these strips is $4.5 \mathrm{~km}$. Highest elevation is at the top of the first three strips labeled: (i). Lowest elevation is at the bottom of the final three strips labeled (iii). The white boxes indicate the section of data for which full-resolution, slant-range-corrected images were produced (Fig. 5). 
final application. Two products are discussed here, namely survey digital image strips and full-resolution digital images. Survey-product images illustrate the individual channel responses at $\mathrm{C}, \mathrm{L}$ and $\mathrm{P}$-bands for $\mathrm{HH}, \mathrm{VV}$ and $\mathrm{HV}$ linear polarizations. These products are slant-range images for incidence angles from nadir up to $55^{\circ}$ (Fig. 4) in which individual pixel values represent the back-scatter intensity. Survey products offer an advantage over the full-resolution image products in that longtransect, large-area coverage is possible as opposed to the small-area coverage feasible when processing data to full resolution. Full-resolution images, on the other hand, are processed such that they are fully polarimetric. The full Stokes matrix is recorded for each pixel in the image, thus enabling SAR back-scatter to be synthesized at any specified transmit and receive polarization combination. A full description of the JPL imaging radar polarimeter and data characteristics which are of relevance to the data described here has been provided by Zebker and others (1990). Further reference to the JPL instrument and geophysical applications of polarimetric SAR remote sensing have been given in Drinkwater (1990), Drinkwater and others (1991), and Ulaby and Elachi (1990).

Survey data described in this paper are not absolutely calibrated. Radar-gain corrections have, however, been applied to each individual channel based upon the system performance during external calibrations before and after the Greenland flight. As a result, absolute back-scatter values are estimated to be known to an accuracy of about $\pm 5 \mathrm{~dB}$. Experience demonstrates that the SAR antenna gain is stable (personal communication from A. Freeman, 1991) with small, short-duration fluctuations only. The C-band SAR was particularly stable throughout the 1989 deployments, fluctuating on average by less than $\pm 0.8 \mathrm{~dB}$. L-band was also fairly stable at about $\pm 1.0 \mathrm{~dB}$ while the P-band system is least stable, varying by around $\pm 1.5 \mathrm{~dB}$ during 1989 deployments. Available statistics show the stability of the radar gain over the course of the flight season and all indications are that during a flight of several hours the gain drifts by only a fraction of a $\mathrm{dB}$ (personal communication from $\mathrm{A}$. Freeman, 1991). Channel imbalance is particularly important for subsequent intercomparisons of data. The calibration flights undertaken in Europe immediately after the Greenland flights indicate that the C- and Lband SARs have HH/VV imbalances less than $+0.5 \mathrm{~dB}$. The P-band radar calibrations indicated that this system showed the largest channel imbalance of up to $+2 \mathrm{~dB}$ for $\mathrm{HH} / \mathrm{VV}$ co-polar responses. Noise-equivalent backscatter coefficients at C- and L-bands are about -35 and $-40 \mathrm{~dB}$, respectively. A full description of the calibration of the SAR has been given by Freeman and others (in press), and descriptions of channel imbalance correction measures have been further discussed by Drinkwater and others (1991).

One scene of full-resolution data was processed, from which the C- and P-band total-power images are shown in Figure 5. The irregular upper edge of the data corresponds to nadir incidence and the unevenness in the position of the edge is a consequence of surface topography. The dimensions of the image are approximately $12 \mathrm{~km}$ along track by $8 \mathrm{~km}$ across the swath, while the maximum incidence angle in Figure 5 is approximately $62^{\circ}$.

Examination of the principal components of the survey-product data set showed that polarization information contained within a single frequency was correlated and furthermore that the main source of variation in the nine-channel survey data set was between the different frequencies. Thus, before proceeding further in the analysis, the pixel intensities among the individual polarization channels and for each frequency were averaged to reduce speckle. Averages of the C-, L- and P-band polarization data are shown in Figure 4, which
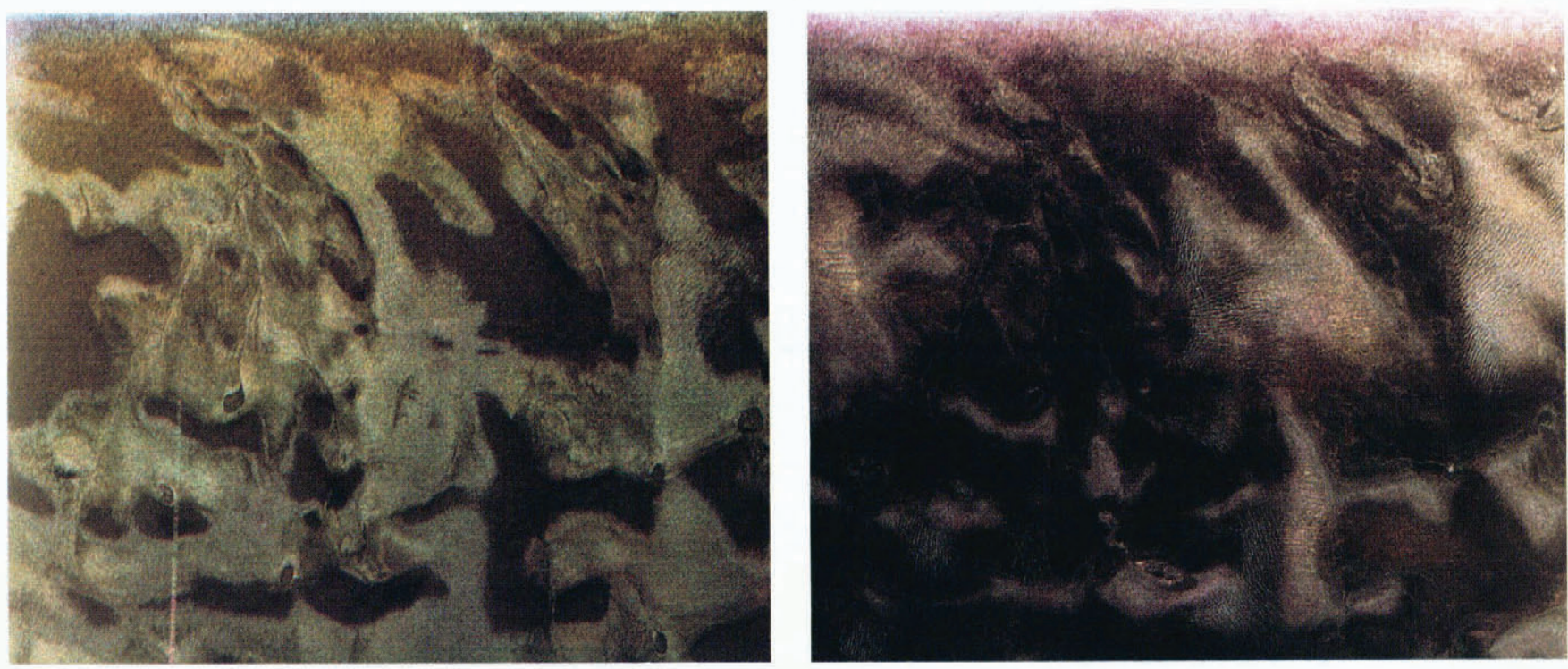

Fig. 5. C- (left) and P-band (right) full-resolution, slant-range-corrected, four-look data. Polarization data are coded by color: HH-red; VV-green; HV-blue. The intensity of each image is modulated by the total power. The dimensions of the image are approximately $12 \mathrm{~km} \times 8 \mathrm{~km}$ and the pixel size is $12.1 \mathrm{~m}$ by $6.6 \mathrm{~m}$ (azimuth $\times$ range). 
represents data collected between incidence angles of 20 $55^{\circ}$.

There is little detail present in the survey data shown in Figure 4 over the highest elevations (top of the three strips labeled (i) at left) of the flight line. This situation changes at lower elevations where there are complex intensity patterns evident at all channels. Based on previous experience with STAR-1 Intera X-band (HHpol) and SEASAT L-band ( $\mathrm{HH}-$ pol) SAR data collected in the same general vicinity of the 1989 data, many of the most prominent features appear to be related to glacier lake and stream systems. An unexpected outcome of the multi-frequency comparison is the identification of contrast-reversed areas. The effect is particularly evident in the parts of the images enclosed in the two white boxes in Figure 4. For example, the bright, vaguely arrowshaped patch that appears just above the center of the box drawn in the P-band image appears dark in the corresponding C-band image. These same areas of contrast reversal are very evident in the full-resolution, slant-range-corrected image in Figure 5. As described later, we suspect this is related to frequency-dependent penetration depths and differences in physical properties between the near surface and deeper snow and firn.

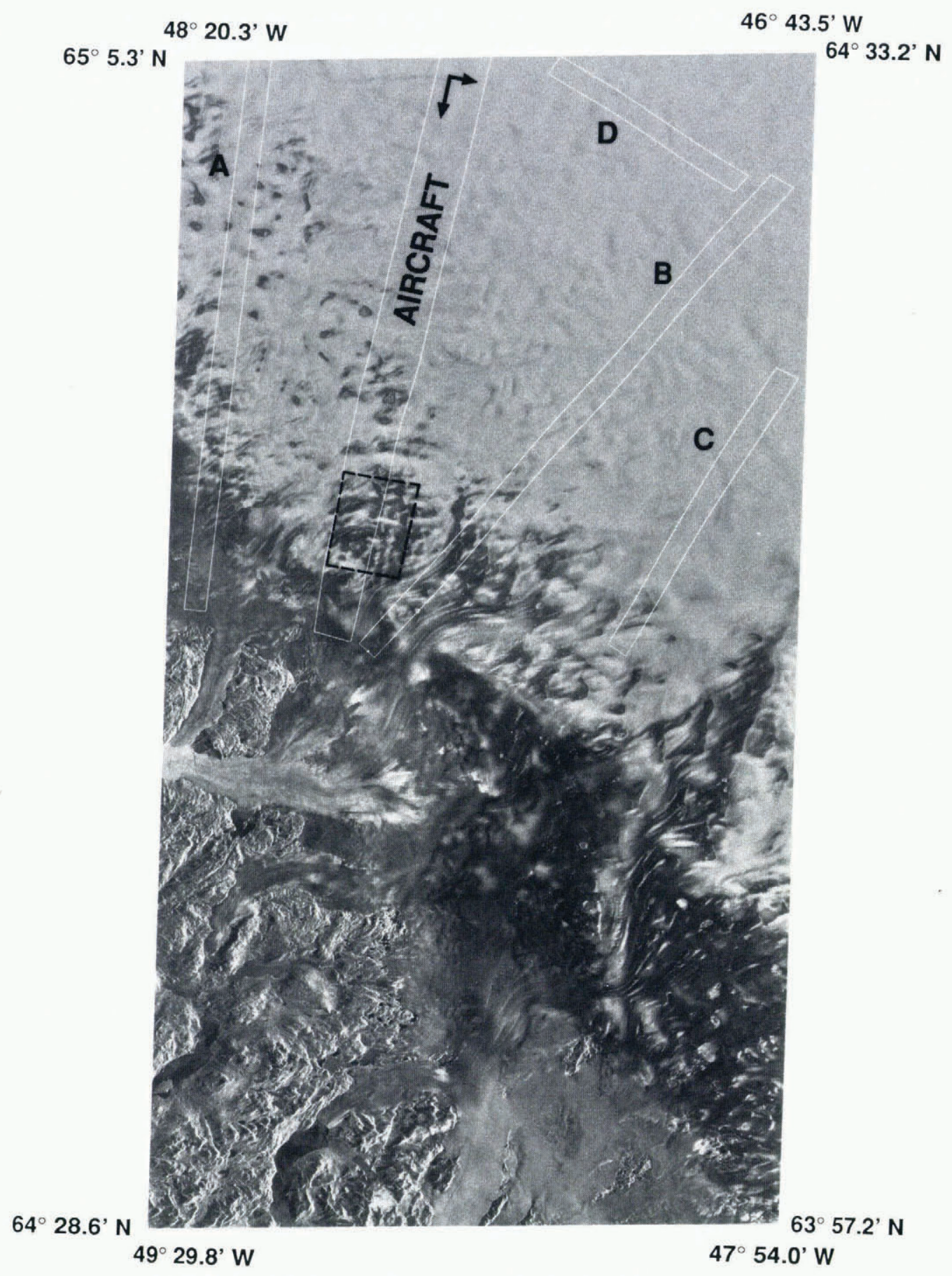

Fig. 6. Co-registered L-band SEASAT and multi-frequency aircraft SAR swaths indicating locations of the aircraft $S A R$ track (AIRCRAFT) and other samples of data $(A-D)$ discussed in section 6 . The flight and radar-look directions are indicated by the arrows for the strip of aircraft SAR survey-processed data. The black dashed rectangular box shows the location of the full-resolution image presented in Figure 5. 
Figure 5 shows two-color-classified polarimetric total power images of the same area taken from the strip in Figure 4 at C- and P-band. Each polarization combination is overlaid on the total-intensity image as a color, where the two linear co-polarizations $(\mathrm{HH}$ and $\mathrm{VV})$ are denoted by red and green, and linear cross-polarization (HV) by blue. The resulting neutral hues and the lack of any predominant color saturation in this scene confirms that little independent information is contained in the amplitudes recorded at the various polarization combinations. However, this in itself is an important observation, since it requires that the mechanisms of scattering be limited to combinations of geometric optics and volume scattering consistent with early results by Swift and others (1985). Another observation from Figure 5 is that surface, or perhaps sub-surface crevasses are more clearly observed at P-band than at C-band. Those areas identified as having extensive systems of fractures at Pband are in many instances obscured in the C-band image due to contrast reversal. This may be because the P-band has the ability to "see" deeper into wet firn, whereas the C-band energy is absorbed before it penetrates deep enough to image deep crevasses. Thus, where wet firn does not mask the buried crevasses, the shorter C-band wavelength also has the capability of imaging these sub-surface features. This is borne out by the fact that those areas of crevasses which can be observed at C- and P-bands also tend to be bright (interpreted as areas of relatively dry firn) at both frequencies.

To give some perspective to the information contained in relatively narrow swath, airborne SAR data, survey and full-resolution products have been co-registered with SEASAT data; the location of the airborne data is shown in Figure 6. Two consecutive frames of SEASAT data (in Fig. 6) were digitally mosaicked and merged with an overlap of about $10 \%$. These images were acquired from a swath of data obtained over western Greenland on a descending orbit (rev. 1490) on 9 October 1978. Though somewhat later than the time of year in which the aircraft data were collected, this large area mosaic (approximately $100 \mathrm{~km} \times 200 \mathrm{~km}$ ) places the aircraft data in the

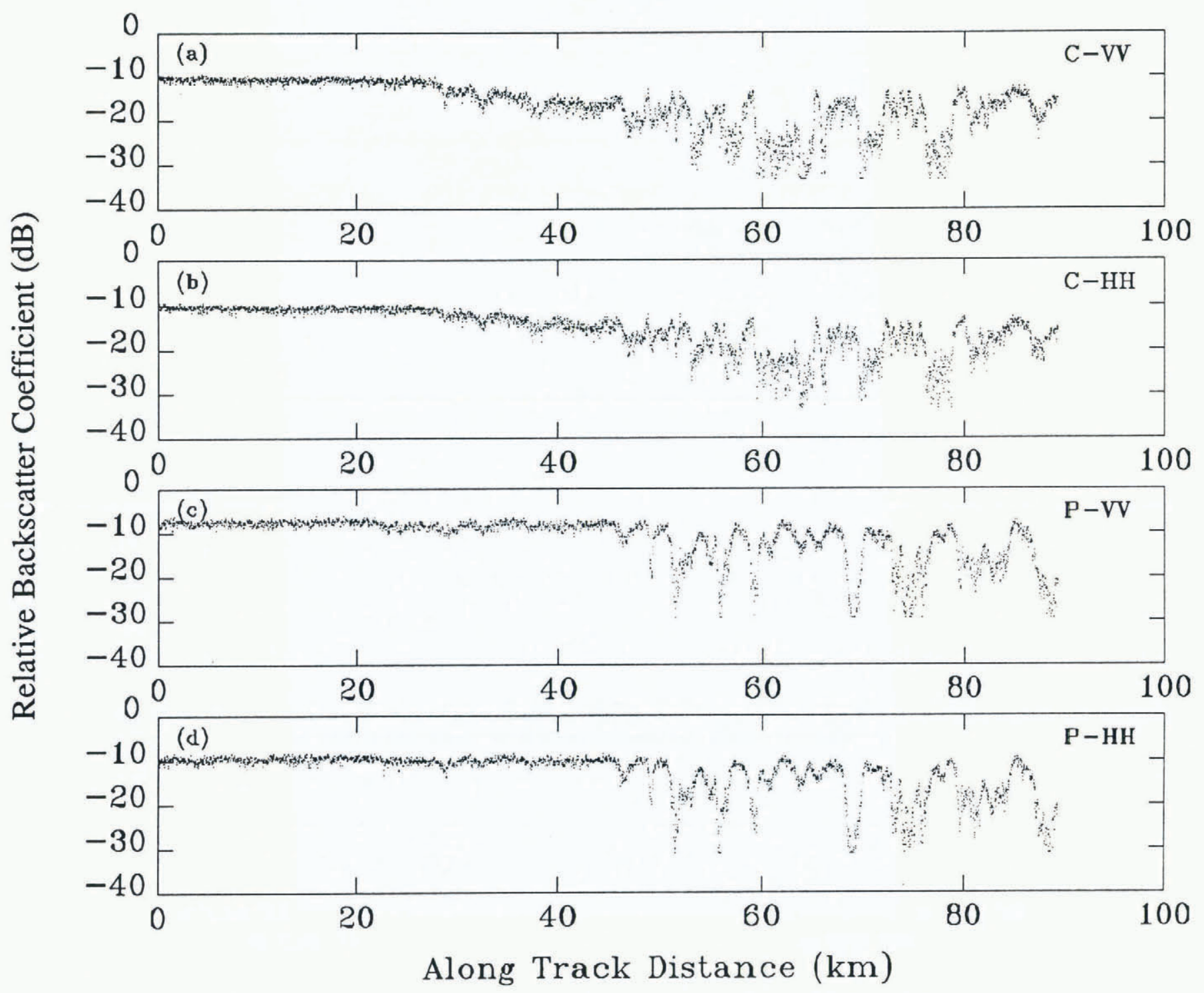

Fig. 7. Profile of the mean of ten pixels located in the center of the SAR imagery along the flight line. Profile (a) shows $C$-band VV-pol data; (b) shows $C$-band HH-pol data; (c) shows P-band VV-pol data; and (d) shows P-band HHpol data. 
context of regional patterns and surface morphologies and topographies which influence surface snow and ice properties. In fact, the general patterns and tonal variations characteristic of the P-band image in Figure 5 can be identified in the corresponding part of Figure 6 .

The most striking feature of Figure 6 is the surface mottling associated with the boundary zone between the accumulation zone (generally the bright, featureless areas in the upper parts of the image) and the seasonal melt zone (darker areas). By October, the surface is beginning to cool and is expected to be largely dry above the snow line (the boundary below which seasonal snow largely melts in the summer). Below the snow line, the darker tones and patterns may be indicative of either residual wetness or smooth, bubble-free ice, either property causing increased reflection of energy away from the SAR.

From the SEASAT data, it is apparent that the multichannel airborne data were collected over the somewhat featureless upper reaches of the ice sheet, continuing downslope through regions of increasing density of surface lake and stream systems, and finally into the ablation area of the ice sheet. Indeed, there is little detail present in the slant-range survey data shown in Figure 4 over the highest elevations.

To simplify data interpretation, a ten-pixel swath along the center line of the survey data was selected (approx. 42-43 incidence angle) and the pixels averaged together. Data values produced down the length of each data strip are shown as profiles in Figure $7 \mathrm{a}-\mathrm{d}$. These plots illustrate that the range of variability observed in these channels approaches the dynamic range of the 8 bit recording system (i.e. 256 intensity levels or $24 \mathrm{~dB}$ range). Low back-scatter values below $-30 \mathrm{~dB}$ approach and may be limited by the noise-equivalent back-scatter value of the radar (limited to about $-35 \mathrm{~dB}$ at boresight due to thermal noise).

Figure $7 \mathrm{a}$ and $\mathrm{b}$ shows the $\mathrm{C}$-band profiles at $\mathrm{HH}$ and VV polarization. Immediately obvious is the high value of relative back-scatter coefficient (about $-10 \mathrm{~dB}$ ) at high elevations followed by a sloping ramp starting at about $27 \mathrm{~km}$ along track. The ramp terminates at about $47 \mathrm{~km}$ in a zone of reduced average (about $-22 \mathrm{~dB}$ ) but more strongly varying relative back-scatter coefficient. Referring back to Figure 3, this intensity signature is believed to be characteristic of snow facies changing from mostly dry to wet and saturated snow. Back-scatter is high in the drier firn regime where volume-scatter dominates the signal. As the firn wetness increases, penetration decreases while forward-scatter increases, causing a net decrease in back-scatter until the point where the snow is fully saturated with water. Back-scatter variability increases as morphologic features such as lakes and crevasses become more prevalent nearer the ice-sheet margin.

A similar ten-pixel average down the flight line is shown for the P-band data in Figure 7c and d. There is similar overall dynamic range and similar variability in the data over the drier firn areas at P-band as compared to C-band but there is much less of a transitional ramp between the areas we interpret as drier and saturated firn. In fact, when smoothed VV-polarized data are plotted in Figure 8 on a linear rather than logarithmic scale, the P-

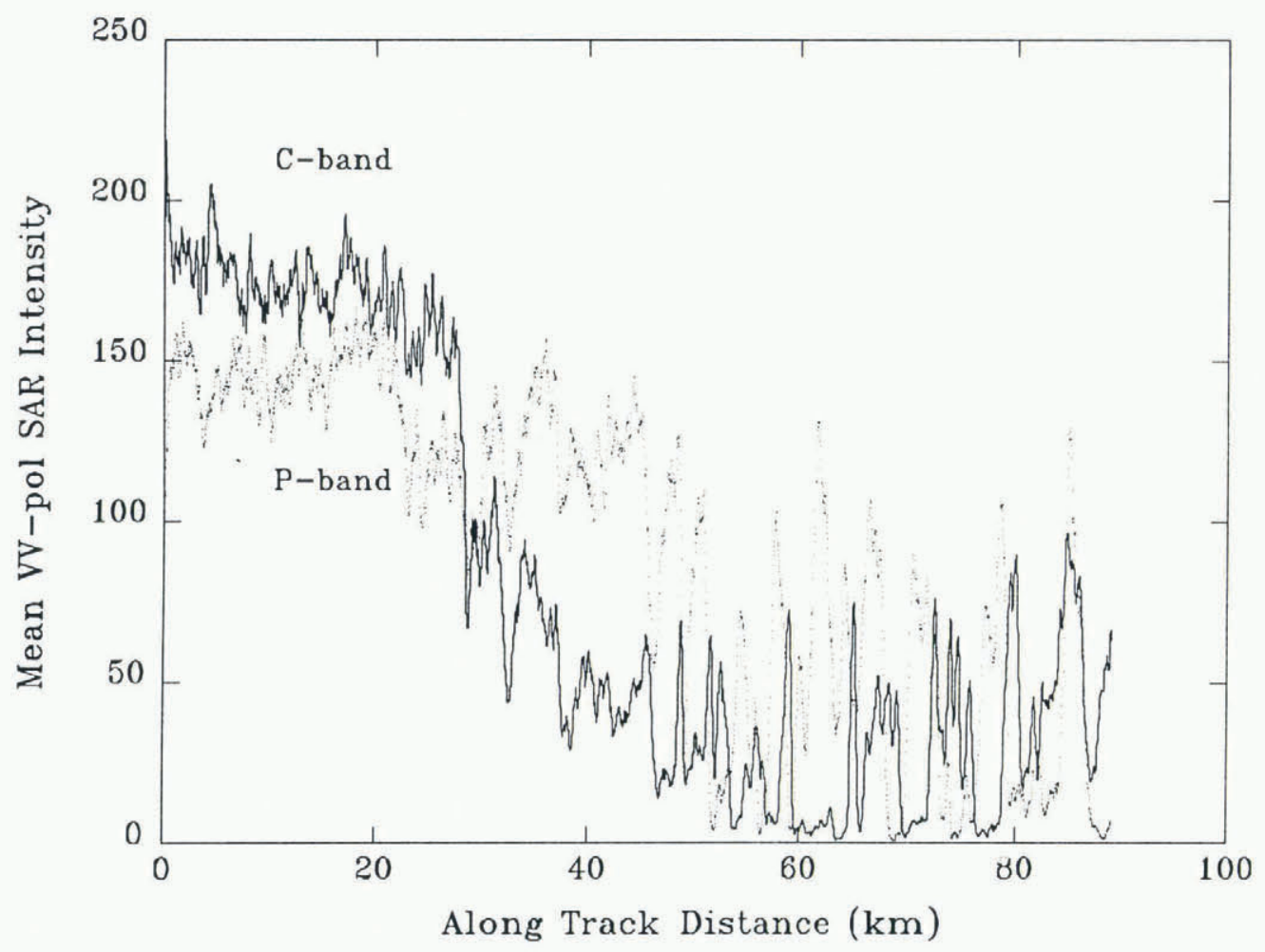

Fig. 8. C-band (solid curve) vs P-band (dotted curve) mean VV-pol back-scatter intensities downslope. Each profile is smoothed using a ten-point filter (running average) in order to highlight the large-scale features and to remove fading or speckle fluctuations. 
band profile is characterized by a sequence of en échelon steps with the most abrupt changes taking place around 22 and $37 \mathrm{~km}$ along track (Jezek and others, 1990). Minima in the rightmost part of the P-band data in Figures 7 and 8 correspond with surface lakes.

\section{MODELING RESULTS}

To account for these observations quantitatively, models were developed that include variations in angle of incidence, complex permittivity, volume inhomogeneities and surface roughness. C- and P-band modeling results are presented to describe the extremes of ice-sheet radar signatures detected at these two frequencies.

Power received at the radar is determined in part by the geometrical properties of the scattering surface and in part by the electrical properties of the surface. Values for the complex dielectric constant $\varepsilon^{*}$ (where $\varepsilon^{*}=\varepsilon^{\prime}+i \varepsilon^{\prime \prime}$ ), which were derived from dielectric mixture formulas, are used in the following analyses and are listed in Table 1. These values are consistent with results from measurements published by Hallikainen and others (1982) and Mätzler (1987). The imaginary part of the permittivity, $\varepsilon^{\prime \prime}$, is seen to vary strongly with snow wetness and with frequency. In contrast, the real part of the permittivity, $\varepsilon^{\prime}$, has a weak dependence on frequency when free water is present.

The roughness controling scattering from the surface of a glacier is most likely to be on the sub-meter scale or greater. Sub-meter roughnesses such as sastrugi characterize much of the ice sheet but in the dry-snow areas these are likely to be of minimal importance because the Fresnel reflection coefficient is small (on the order of 0.14) and thus such features are largely transparent to microwave energy. As to likely values for surface roughness, Ulander (1987) and Drinkwater and Dowdeswell (1987) have used Ku-band radar-altimeter data to obtain estimates of the r.m.s. roughness scales on the surface of the Greenland ice sheet and Svalbard ice caps. They obtained values of between 0.5 and $6.0 \mathrm{~m}$ from the characteristics of altimeter wave-form data from along- track range data at a several kilometer footprint scale.

Here, we ignore the small-scale surface roughness and consider the surface to have normally distributed roughness elements with an autocorrelation function which approximates a Gaussian distribution, i.e. $p(\xi)=\exp \left(\xi^{2} /\right.$ $\left.L^{2}\right)$. Having made that assumption, we estimate the backscatter from these surfaces. Three roughness classes are chosen for a glacial surface in order to depict the effects upon the back-scatter as a function of incidence angle. These surface classes have r.m.s. slopes of $5.7^{\circ}, 17.2^{\circ}$ and $28.7^{\circ}$ (i.e. $0.1,0.3,0.5 \mathrm{rad}$, respectively), corresponding to relatively smooth, medium rough and very rough. For a Gaussian function, the r.m.s. slope $m=1.41\left(\sigma_{\mathrm{h}} / L\right)$, where $\sigma_{\mathrm{h}}$ is the r.m.s. height and $L$. is the correlation length. Thus, for the roughness classes noted, and an example r.m.s. height of $1.0 \mathrm{~m}$, the corresponding values of $L$ would be approximately $14.1,4.7$ and $2.8 \mathrm{~m}$. The first class is typical of undulations in the surface caused by broad-scale glacier dynamics, while the latter may be more typical of snow dunes and shorter-wavelength corrugations of the surface. At these scales, the geometric optics limit is applicable in scattering simulations, since the standard deviation of surface roughness is greater than one-third of a wavelength, and the correlation length scales are much greater than one wavelength ( $P$ band $(0.44 \mathrm{GHz}) ; \lambda=0.68 \mathrm{~m})$. Additionally, the arbitrary r.m.s. height could be chosen differently, thus resulting in a different set of correlation lengths, yet the r.m.s. slope and results would remain the same due to the scaling of $\sigma_{\mathrm{h}} / L$.

This simple geometric optics model is coupled with a Rayleigh scattering volume of infinite depth in order to obtain a first-order estimate of back-scattering coefficient variability as a function of surface roughness and snow parameters. For surface scattering, a Kirchhoff formulation has been used with a stationary-phase approximation. In the volume-scattering model, a simple cloud approximation is utilized assuming isotropic spherical scatterers randomly distributed throughout the snow volume.

Figure 9a shows the simulated C-band back-scatter response of a typical dry-snow surface with a snow density

Table 1. Snow dielectric properties as a function of density and wetness

Complex dielectric constant

Density wetness (by volume) C-band $\quad L$-band $P$-band

$\begin{array}{llll}0.35 \mathrm{Mg} \mathrm{m}^{-3} & \varepsilon^{*}=1.66+i 0.001 & \mathrm{e}^{*}=1.66+i 0.0005 & \mathrm{e}^{*}=1.66+i 0.0005 \\ \begin{array}{ll}0.35 \mathrm{Mg} \mathrm{m}^{-3} \\ 6 \%\end{array} & \mathrm{e}^{*}=2.08+i 0.3 & \mathrm{e}^{*}=2.25+i 0.09 & \mathrm{e}^{*}=2.26+i 0.03 \\ \begin{array}{l}0.35 \mathrm{Mg} \mathrm{m}^{-3} \\ 15 \%\end{array} & \mathrm{e}^{*}=3.29+i 1.07 & \mathrm{e}^{*}=3.89+i 0.32 & \mathrm{e}^{*}=3.39+i 0.12\end{array}$


(a)

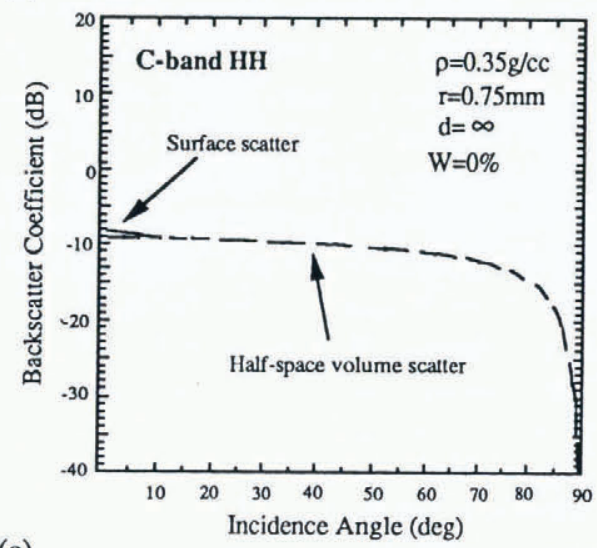

(c)

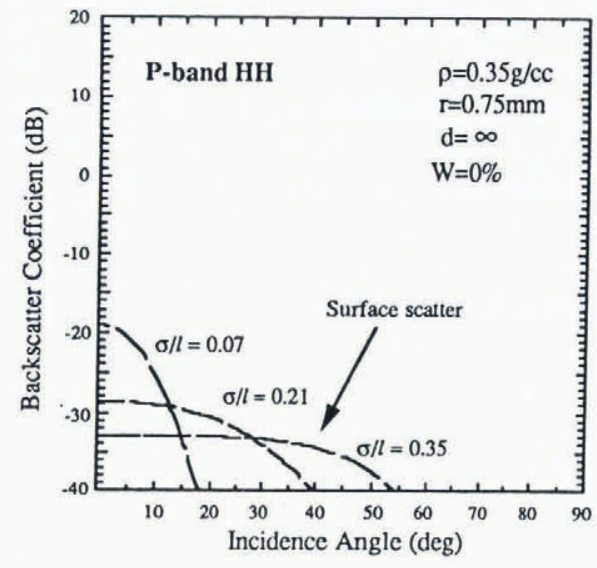

(b)

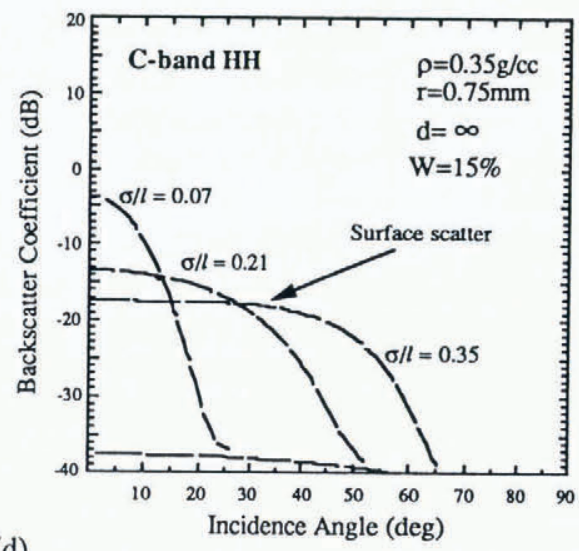

(d)

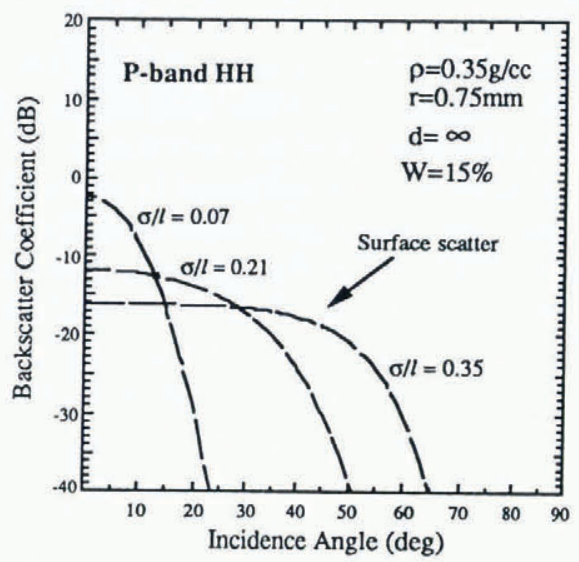

Fig. 9. Predicted HH-polarized scattering response using Kirchoff rough-surface scattering model coupled incoherently with a Rayleigh-scattering volume: (a) back-scatter response of dry snow at $5.3 \mathrm{GHz}$; (b) back-scatter response from wet snow at $5.3 \mathrm{GHz}$; (c) back-scatter response of dry snow at $0.4 \mathrm{GHz}$; (d) back-scatter response of wet snow at $0.4 \mathrm{GHz}$.

of $0.35 \mathrm{Mg} \mathrm{m}^{-3}$ and mean snow-grain diameter of $1.5 \mathrm{~mm}$. In this case, the snow wetness $W$ is $0 \%$ by volume and the depth of snow is considered a half space of infinite volume. The $5.3 \mathrm{GHz}$ response is dominated by volume-scattering by the snow grains. Since grains are assumed to be spherical, the $\mathrm{HH}$ returns are identical to the VV returns with a level of around $-10 \mathrm{~dB}$ over most of the incidence angle range, tapering off rapidly beyond $70^{\circ}$ incidence. Increasing the snow wetness to about 15\% effectively extinguishes volume-scattering at C-band (Fig. 9b) with residual levels below $-35 \mathrm{~dB}$. Without the addition of a significant volume term, the total or aggregate backscatter coefficient is reduced in magnitude. The VVpolarized response is equal to the $\mathrm{HH}$-polarized response, since in the stationary phase approximation planeboundary reflection is assumed at each point on the surface. At $43^{\circ}$, which is the incidence angle at which survey-image statistics were derived, the surface with $\sigma_{\mathrm{h}}$ / $L=0.35$ has a C-band back-scatter coefficient which is reduced from approximately $-10 \mathrm{~dB}$ (for dry snow) to approximately $-20 \mathrm{~dB}$ (for wet snow). The above model results are consistent with the along-track variations in back-scattering strength presented in Figure $7 \mathrm{a}$ and $\mathrm{b}$. However, the parameter fit applied for dry snow at Cband indicates a snow-grain diameter of the order of $1.5 \mathrm{~mm}$, and it is not known whether this is consistent with snow or firn under similar conditions at this location during this time of year. Choosing a smaller grain radius of $0.5 \mathrm{~mm}$ reduces the back-scatter level by about $3 \mathrm{~dB}$, but does not modify the gradient or shape of the backscatter curve in the range of incidence angle imaged by the SAR. No surface data were collected at this location and this time of year in order to validate these model results and the parameterization used.

Model simulations at $5.3 \mathrm{GHz}$ are consistent with the hypothesis that wet-snow areas appear relatively darker than dry-snow areas in the C-band SAR images. At this wavelength and roughness scale, the incidence angle is predicted to modulate the mean intensity of dark (wet) areas rather more strongly than bright (dry) areas (Fig. $9 \mathrm{a}$ and b) and, indeed, this seems to be the case in the fullresolution imagery (Fig. 5). This indicates that surface scattering is the dominant term in the case of dark areas we interpret as wet snow. On the other hand, the brightest areas in the central part of the image retain an even tone across the incidence-angle range displayed in the high-resolution scenes (between $0^{\circ}$ and $62^{\circ}$ incidence). This lack of angular dependence is a strong indication that volume-scattering is the dominant term in bright areas we interpret as consisting of dry snow.

Figure $9 \mathrm{c}$ and $\mathrm{d}$ shows the back-scattering response at P-band (68 cm wavelength) from the same dry- and wet- 
snow systems. In Figure 9c, the volume-scattering term diminishes almost completely, falling close to the systemnoise floor of the radar. At these longer wavelengths, the snow crystals do not provide significant Rayleigh scatter, with the result that the surface-scattering term is dominant but weak $(-35 \mathrm{~dB}$ for the roughest surface at about $45^{\circ}$ angle of incidence). This model result is not supported by the survey data which apparently yield a larger back-scatter coefficient. We suspect the increased level of back-scattered energy is associated with largersized buried objects, most likely ice lenses and ice pipes, that contribute to the total received power. Given that the $68 \mathrm{~cm}$ wavelength signal will penetrate into the firn, such volume-scattering is the only explanation for such a high level of back-scatter (about $-10 \mathrm{~dB}$ in Figure $7 \mathrm{c}$ and d).

Figure 9d shows that the wet snow P-band backscatter level at $45^{\circ}$ is close to $-16 \mathrm{~dB}$, and about that which is observed for the mean level at lower elevations in Figure $7 \mathrm{c}$ and $\mathrm{d}$. This level is also comparable to, though slightly greater than the corresponding mean C-band level, as also suggested by the model. We postulate that the small difference between the mean P-band backscatter levels at higher elevations and the maxima in the P-band levels at lower elevations is attributable to attenuation of the volume-scattering component in this wet-snow regime.

What is not predicted by the model in Figure 9 is the magnitude of the observed contrast reversals between Cand P-band. At lower elevations the majority of the areas which were dark at C-band now become bright, and vice versa. Increasing the volume fraction of free water significantly increases the reflectivity of the snow surface (Fig. 9d). This in turn causes an increase in the backscatter of the roughest-surface class to a level of approximately $-18 \mathrm{~dB}$. For the rough-surface class, wetsnow areas have a 1 or $2 \mathrm{~dB}$ higher return at $\mathrm{P}$-band than at C-band because of a slightly greater dielectric contrast at the lower frequency (see Table 1). Dielectric contrast alone, however, does not seem to support the magnitude of the observed intensity contrast at the two frequencies, nor does the model correctly predict the peak intensities observed in the wet-snow zone. Presumably, decreasing penetration depth at the higher frequencies shuts off the volume-scattering component at C-band, whereas volume-scattering from buried crevasses or ice lenses remains significant at P-band. These observations suggest that more detailed modeling efforts are required in order to elucidate the effects of varying penetration depths and sub-surface volume-scattering from ice lenses or crevasses.

\section{POLARIZATION}

Penetration into the dry snow and volume effects cause the like-polarization channels to behave similarly, as seen in Figure 10 where we plot a polarization ratio. The $\mathrm{P}$ band co-polarization ratio is nearly constant in magnitude with near-zero (approximately 2) mean within the uncertainty of the channel imbalance. Minimal variab-
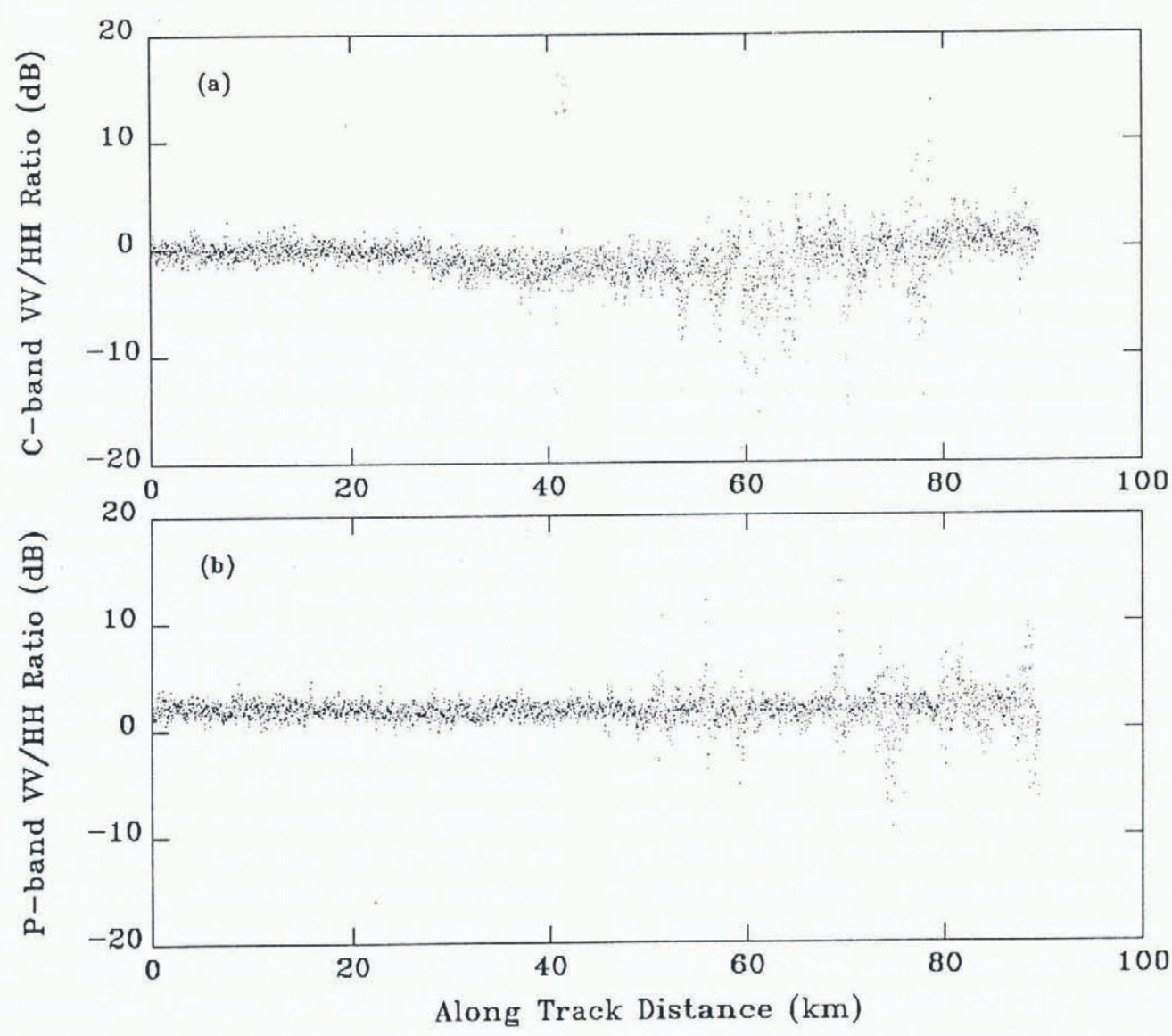

Fig. 10. Profile of the VV/HH co-polarization ratio downslope. (a) Upper plot shows C-band co-polar ratios; (b) lower plot shows P-band co-polar ratios. 


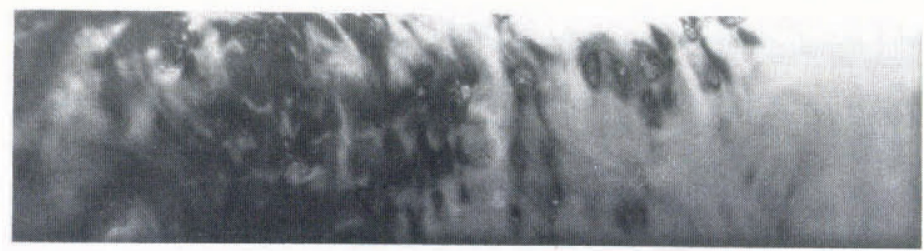

PHH

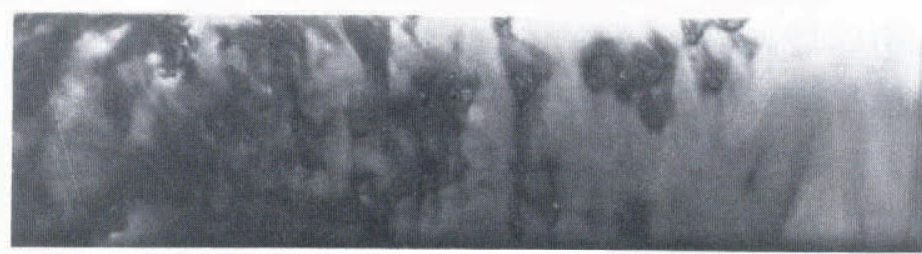

LHH

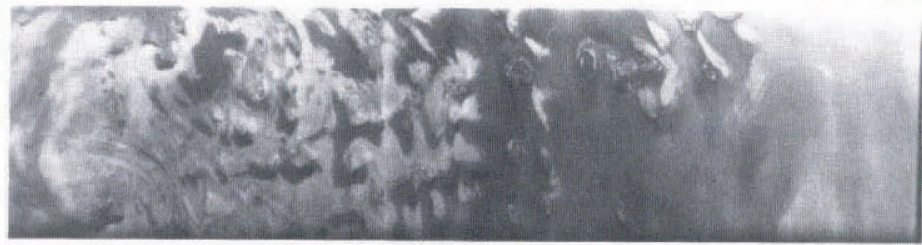

СHн

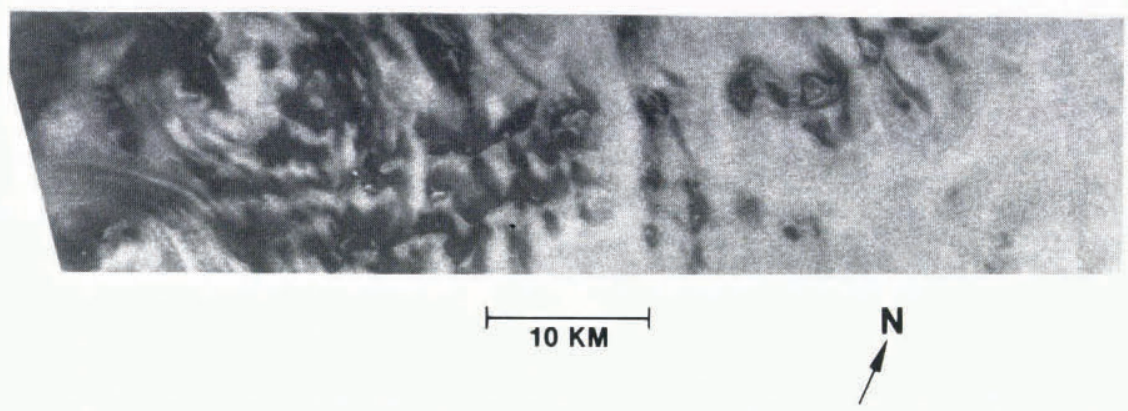

SEASAT

Fig. 11. Comparison between slant-range corrected airborne (a) $P$-, (b) L-, and (c) C-band HH-polarized data, and (d) SEASAT slant-range corrected data. Note that the $10 \mathrm{~km}$ scale applies to the upper strips of airborne SAR data. The SEASAT scale is slightly larger, but no along-track scale change is applied which could distort the original features. Patterns of surface lakes are well correlated, which we take as an indication of constant glacial dynamics over the 12 year period.

ility in the mean value throughout the entire data set supports the contention that volume-scattering and geometrical optics effects are the dominant scattering mechanisms. The C-band co-polar ratio behaves similarly through $25 \mathrm{~km}$ along the ground track. There is a subsequent drop in the co-polar ratio followed by increasing variability and, at the very end of the data set, increasing polarization and mean ratios above 1 (i.e. $\mathrm{HH}>\mathrm{VV}$ ). These later observations suggest that surface scatter may become important in the saturated snow and ablation facies.

Finally, note that the broad trends in the profiles shown in Figures 4, 8 and 10 are interrupted at the lower elevations by large spikes. From visual interpretation of the images, we believe these spikes correspond to the locations of surface lakes. It is clear from Figure 8 that the C-band and P-band data are responding very differently in these areas and indeed many of the bright spikes in Cband are dark areas in P-band. We offer the following speculation that perhaps some of the lakes have already begun to freeze over. Thin snow cover, air bubbles or fractures in the ice cover may be sufficient to cause backscatter at C-band but the density or size of the inhomogeneities is insufficient to cause important scatter at P-band.

\section{COMPARISON WITH SEASAT DATA}

One of the most interesting attributes of the data set becomes apparent after careful comparison of texture and contrast patterns evident in the survey data with similar features in the SEASAT data. Curvilinear patterns related to glacial lake and stream systems apparent in Figure 4 are clearly related to similar features in the SEASAT image shown in Figure 6. The similarity is made more evident by comparing a section of the SEASAT image with a corresponding section of synoptically processed ground-range-corrected airborne data. The result, shown in Figure 11, suggests a strong correlation between spatial patterns of intensity which we believe are predominantly associated with surface lakes. That such a correlation exists is explained qualitatively by assuming first that glacier-flow patterns have remained essentially unchanged over the past 10 years and, secondly, that glacier hydrologic patterns are controled by invariant bottom topography. Thus, while ice may be moving through the imaged areas, the locations of surface lakes are tied to depressions in the ice-sheet surface which are in turn associated with basal relief. We cannot be sure that there has not been significant displacement of the features because we do not have absolute coordinates for either 


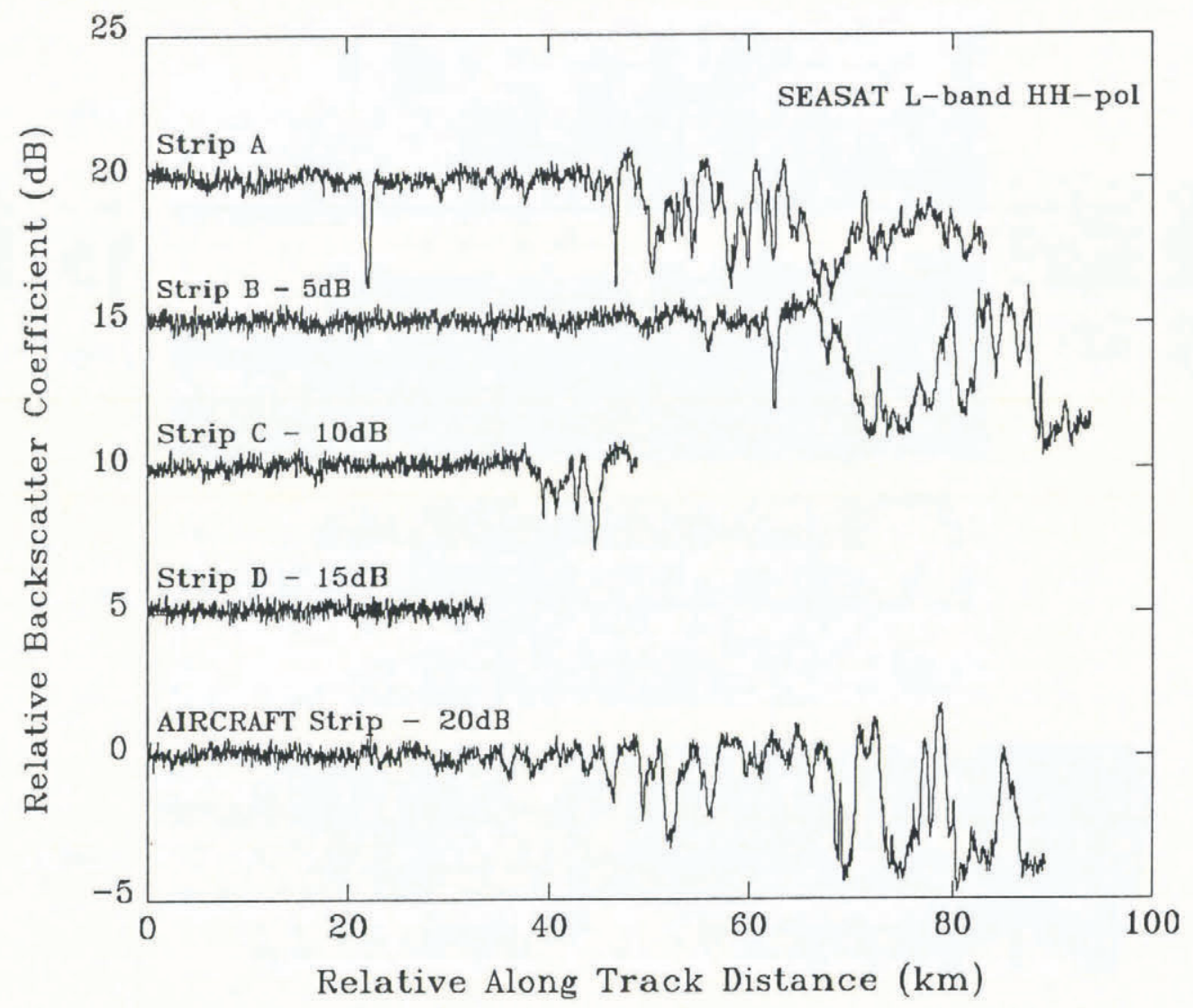

Fig. 12. Spatially smoothed SEASAT SAR data collected over the five areas identified in Figure 6 and offset from strip A by increments of $-5 d B$.

data set. However, it seems unlikely that features dispersed along almost $80 \mathrm{~km}$ of range would all be flowing at the same rate downslope.

A more quantitative correlation between SEASAT and survey-processed airborne-SAR data can be made by comparing pixel intensities computed along profiles through the data sets. Before a direct comparison is possible, it is necessary to establish the integrity of the digitally mosaicked SEASAT data. To do this, several profiles are extracted from the SEASAT data by averaging ten pixels along the center line of the strips labeled A-D, and along the aircraft track in Figure 6. These spatially averaged strips are plotted in Figure 12 starting with strip A and at successively greater offsets (at intervals of $-5 \mathrm{~dB}$ ) for each of the others. The resulting back-scatter profiles indicate that the statistics within the SEASAT image are consistent and independent of antenna-pattern effects. Samples A, B and C show that the patterns of L-band $\mathrm{HH}$-polarized back-scatter are generally similar despite the location when traced across the image and in the downslope direction. Equally importantly, those strips crossing the image-mosaic boundary also do not show a step in pixel intensity, thus implying that no artificial intensity changes have been introduced into the digital data.

To compare directly the satellite and airborne SAR back-scatter data along the aircraft track (labeled AIRCRAFT in Figure 6), the spatially smoothed SEASAT data, from the bottom strip in Figure 12, are plotted alongside the overlapping airborne L-HH survey data in Figure 13. The SEASAT data in this comparison are scaled by adjusting the level of the back-scatter coefficient in the upper-elevation dry-snow region to match that observed in the high-resolution airborne SAR data acquired at $23^{\circ}$ incidence in the same location. We find that the mean $\mathrm{HH}$-polarized intensity at L-band falls between the intensity values at the limiting frequencies. However, the down-glacier variation in contrast is minimum at L-band. Fluctuations along the profiles are well correlated as might be expected if patches of low back-scatter strength are associated with surface lakes and surface melt. The amplitude of the SEASAT-data fluctuations seems damped relative to the airborne data and that may be a consequence of the different incidence angles of these data and the onset of lake freeze-up at the end of the summer season when the SEASAT data were acquired.

\section{SUMMARY}

Based on the analysis presented above, we offer a descriptive model of the fashion in which snow facies are manifest in SAR imagery. Drier snow facies interrupted by intermittent ice lenses strongly scatter the SAR signal at all frequencies. Strong signals characterize this region, because the important scatterers, individual snow grains at C-band and ice lenses at 


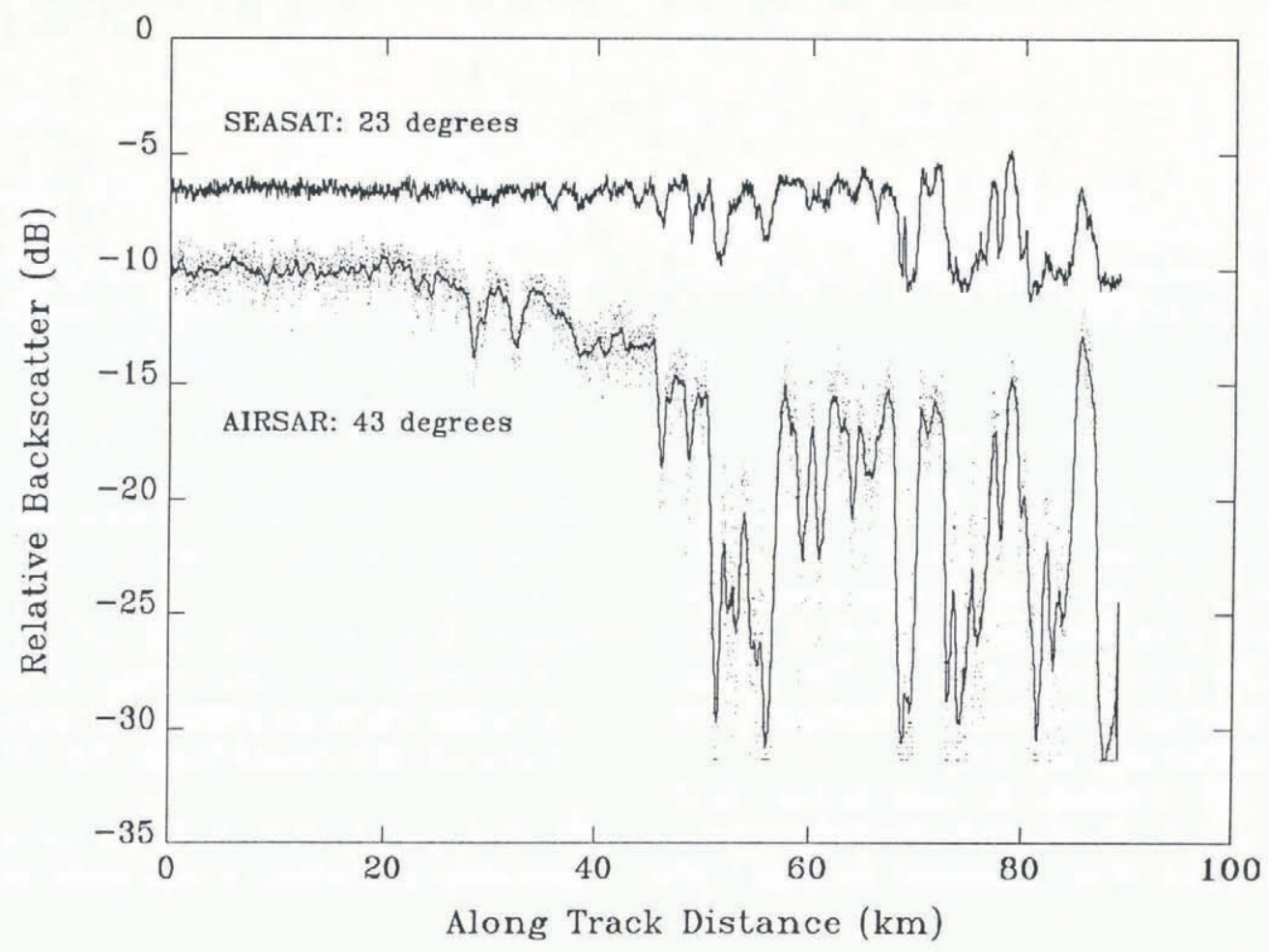

Fig. 13. Spatially smoothed SEASAT SAR and airborne L-HH SAR survey data collected over the region identified in Figure 6 and crossing the area shown in Figure 11.

C-band, L-band and P-band, are numerous. Because the ice lenses (Swift and others, 1985) are large at all wavelengths, there is also little difference between the response of either of the like-polarized channels as evidenced by the co-polarization ratio data.

As snow wetness gradually increases, the C-band back-scatter strength decreases more rapidly than the lower-frequency channels because of increasing dielectric contrast at the surface and decreased penetration at Cband. In the saturated-snow zones, there is little penetration and little scatter at C-band. Some volumescatter may still be contributing at P-band. From the increase in co-polarization ratio at the end of the data set, we infer that with rough bare-ice surfaces, small-scale surface scatter may start to become important at C-band. Apparently, those roughness elements are not large enough to cause a similar increase at P-band.

In conclusions, we propose that melt processes largely control the tonal patterns detected in the C-band SAR imagery. This statement seems reasonably well supported by model calculations and suggests that snow-facies boundaries can be delineated on the basis of characteristic trends in back-scatter coefficient down-glacier. We suspect that the $\mathrm{P}$-band response is the result of both snow wetness and large-scale firn morphologies such as ice lenses, due to the increased penetration depth. This hypothesis is supported by qualitative observations such as the contrast reversals between the C- and P-band images, but a corroborative model is yet to be developed. On the basis of these results, we offer the following two predictions: (a) that P-band back-scatter intensity will decrease up-glacier above the dry-snow line, where ice lenses are less numerous; and (b) that there will be a strong seasonal dependence in back-scatter associated primarily with snowmelt.

\section{ACKNOWLEDGEMENTS}

This research was supported under grants from the Polar Oceans and Ice Sheets Program of the Earth Science and Applications Division of the U.S. National Aeronautics and Space Administration. Work performed by M. R. D., J. P. C. and R.K. was carried out at the Jet Propulsion Laboratory, California Institute of Technology, through an agreement with NASA.

\section{REFERENCES}

Benson, C. S. 1961. Stratigraphic studies in the snow and firn of the Greenland ice sheet. Folia Geographica Danica, 9, 13-37.

Bindschadler, R. A., K. C. Jezek and J. Crawford. 1987. Glaciological investigations using the synthetic aperture radar imaging system. Ann. Glaciol., 9, 11-19.

Bindschadler, R. A., H.J. Zwally, J. A. Major and A. C. Brenner. 1989. Surface topography of the Greenland ice sheet from satellite radar altimetry. Washington, DC, National Aeronautics and Space Administration. (NASA SP503.)

Drinkwater, M. R. 1990. Multi-frequency imaging radar polarimetry of sea ice. In Murthy, T. K. S., J. G. Paren, W. M. Sackinger and P. Wadhams, eds. Ice technology for polar operations. Southampton, Computational Mechanics Publications, 365-376. 
Drinkwater, M. R. and J. A. Dowdeswell. 1987. A multisensor approach to the interpretation of radar altimeter wave forms from two Arctic ice caps. Ann. Glaciol., 9, 60-68.

Drinkwater, M. R., R. Kwok, D. P. Winebrenner and E. Rignot. 1991. Multi-frequency polarimetric synthetic aperture radar observations of sea ice. F. Geophys. Res., 96(C11), 20,679-20,698.

Freeman, A., Y. Shen, J. Van Zyl and J. D. Klein. 1991. Calibration of NASA/JPL DC-8 polarimetric SAR data. In IGARSS '91. Remote sensing: global monitoring for Earth management. 1991 International Geoscience and Remote Sensing Symposium. Helsinki University of Technology, Espoo, Finland, 1-6 June, 1991. Volume III, 1377-1379.

Hallikainen, M., F. T. Ulaby and M. Abdel-Razik. 1982. Measurements of the dielectric properties of snow in the $4-18 \mathrm{GHz}$ frequency range. In 12 th European Microwave Conference Proceedings. Tunbridge Wells, Microwave Exhibitions, 151-156.

Jezek, K. C., J.P. Crawford, R. Bindschadler, M. R. Drinkwater and R. Kwok. 1990. Synthetic aperture radar observations of the Greenland ice sheet. $7 P L$
Publ. 90-56, 21-28.

Mätzler, C. 1987. Applications of the interaction of microwaves with the natural snow cover. Remote Sensing Rev., 2(2), 259-387.

Molnia, B.F. and J.E. Jones. 1989. View through ice. EOS, 70(28), 701-710.

Swift, C. T., P. S. Hayes, J.S. Herd, W. L. Jones and V.E. Delnore. 1985. Airborne microwave measurements of the southern Greenland ice sheet. F. Geophys. Res., 90(B2), 1983-1994.

Ulaby, F.T. and C. Elachi. 1990. Radar polarimetry for geoscience applications. Norwood, MA, Artech House.

Ulander, L. 1985. Airborne radar altimetry over the Greenland ice sheet. (M.Sc. thesis, University of London.)

Zebker, H.A., J.J. Van Zyl and C. Elachi. 1990. Polarimetric radar system design. In Ulaby, F. T. and C. Elachi, eds. Radar polarimetry for geoscience applications. Norwood, MA, Artech House, 273-314.

The accuracy of references in the text and in this list is the responsibility of the authors, to whom queries should be addressed. 